\title{
BURUH DI SENEMBAH MAATCHAPPIJ 1889-1939
}

\author{
Oleh : \\ Lister Eva \\ Tegar Giri Suharseno
}

\begin{abstract}
ABSTRAK
Penelitian ini bertujuan untuk mengetahui keadaan kehidupan buruh di Senembah Maatschappij pada tahun 1889 sampai dengan tahun 1939. Metode penelitian yang digunakan dalam penelitian ini adalah Metode Sejarah dengan Liblary Research untuk mengumpulkan data berupa litelatur, arsip dan dokumentasi. Metode Sejarah menguji dan menganalisa secara kritis data rekaman dan peninggalan sejarah melalui empat tahapan yaitu Heuristik, kritik sumber, interpretasi kemudian penyajian hasil penelitian. Hasil penelitian menunjukkan. Keadaan kehidupan buruh yang sulit dikarenakan diberlakukannya Koeli Ordonnantie yang menerapkan Poenale Sanctie bagi para buruh (kuli). Kehidupan buruh tampaknya semakin membaik, karena direktur utama Senembah Maatchappij masa itu C.W. Janssen menaruh perhatian dengan nasib buruh dengan memberikan buruh tempat tinggal, pesangon bagi pensiunan buruh, pendidikan bagi anak-anak buruh yang menggunakan bahasa Jawa sebagai pengantar, dan fasilitas kesehatan bagi para buruh. Tan Malaka pernah bekerja sebagai guru serta bertugas mengawasi kualitas pendidikan yang diselenggarakan oleh Senembah Maatschappij menulis adanya "Kampung Potekim" yaitu kampung yang sengaja dibuat untuk menunjukkan tingginya kesejahteraan buruh di Senembah Maatschappij. Merupakan fakta yang sangat menarik jika kesejahteraan buruh ternyata hanyalah sebuah pencitraan belaka.
\end{abstract}

Kata Kunci : Buruh, kuli, Senembah Maatschappij, Tan Malaka 


\section{PENDAHULUAN}

Sumatera Timur (Sumatera Ooskust) memiliki sejarah panjang tentang perkebunan khususnya tembakau. Menurut Anderson, masyarakat Melayu di Sumatera timur sudah menanam tembakau sebelum kedatangan orang Barat ke wilayah ini (Pelzer, 1985:21). Selain itu, tembakau yang dihasilkan oleh masyarakat Deli sudah diekspor ke Penang (Said, 1977:9). Sejak kedatangan Jacobus Nienhuys kemudian didirikannya Deli Maatchappij olehnya tahun 1869, kawasan ini terkenal sebagai perkebunan penghasil tembakau dengan kualitas sangat baik yang dikenal dengan sebutan "Tembakau Deli". Keadaan ini membuat semakin banyak para pengusahapengusaha asing yang tertarik ingin mencoba membuka perkebunan di Sumatera Timur dengan komoditi utama yaitu tembakau dan karet.

Selain Nienhuys, Pengusaha-pengusaha lain yang tertarik ingin untuk memulai membuka perkebunan di Sumatera Timur diantaranya adalah Carl Furchtegott Grob dan Hermann Naeher. Grob merupakan seorang pengusaha dari Sisilia berkebangsaan Jerman yang pernah bekerja di Onderneming Helvetia dan Naeher seorang berkebangsaan Swiss. Mereka membentuk sebuah Firma perkebunan yang diberi nama Firma Naeher \& Grob pada tahun 1871 dengan lahan yang berasal dari konsesi lahan di sepanjang Sungai Belumai yang diberikan oleh Sultan Serdang. Firma inilah yang kemudian menjadi cikal bakal berdirinya Senembah Maatchappij.

Namun menjelang tahun 1889, keuntungan-keuntungan firma ini berkurang dikarenakan bergersernya permintaan pasar yang lebih menyukai tembakau berdaun tipis, ditambah lagi dengan adanya penghapusan bea rendah atas tembakau berdaun tebal. Selain itu, kesehatan C. Grob semakin memburuk. Hal ini menyebabkan mereka mencari pihak yang ingin membeli tanah-tanah mereka. Atas anjuran dari Direktur Deli Maatchappij, Firma ini berubah badan usahanya menjadi perseroan (Naamlodze Venootchap) bernama N.V Senembah Maatchappij pada tahun 1889 dan C.W. Jassen menjadi direkturnya.

Setelah berubahnya badan usaha perusahaan, perkebunan ini menambah jenis komoditi tanamannya yaitu karet dan kopra. Perkebunan karet dibuka di kawasan 
Tanjung Garbus, Melati dan Limau Mungkur. Selain itu perkebunan kopra (kelapa) dibuka di kawasan Sungai Tuan. Sarana dan prasarana juga mengalami perkembangan seiring dengan pertambahan komoditi, pabrik karet dan pabrik kopra juga dibangun oleh maskapai ini.

Menurut Pelzer, Maskapai Senembah layak mendapatkan catatan khusus karena sumbangan mereka yang unik kepada pengembangan di bidang sosial yang memperbaiki hubungan pengusaha Onderneming dengan buruh (Pelzer, 1985:60). Pegawai administratif maskapai ini adalah orang-orang Belanda, sementara buruh kebanyakan adalah orang-orang pribumi yang bersuku Melayu, Karo, Jawa dan Tionghoa. Kuli dipekerjakan dengan sistem kontrak (kuli kontrak) dan maskapai ini juga membangun "pondok" atau permukiman yang dikhususkan untuk para kuli. Sekolah dan Rumah sakit pun dibangun sebagai fasilitas yang tersedia untuk para kuli dan pegawai di perusahaan ini. Buruh di Senembah Maatscappij dipekerjakan dengan menggunakan sistem kontrak yang biasa dikenal dengan sebutan "Kuli Kontrak". Di luar pekerjaan mereka, dalam mengisi waktu-waktu luang mereka diperbolehkan berjudi sehingga mereka tetap bergantung pada pinjaman-pinjaman yang diberikan pihak perkebunan dan pada akhirnya mereka memperpanjang kontrak mereka karena terlilit hutang.

Rumah sakit yang dibangun yaitu Hospitaal te Tandjong Morawa yang sebelumnya telah dibangun oleh Firma Naeher \& Grob digunakan sebagai tempat pengobatan tempat penelitian penyakit tropis dan standar kesehatan di perusahaan ini hampir setara dengan standar kesehatan di Eropa. Hal ini di buktikan dengan angka kematian di perkebunan ini relatif lebih rendah dibanding dengan perusahaan perkebunan lainnya. Sekolah yang dibangun oleh maskapai ini yaitu Ambasct School (sekolah teknik) yang berada di Tanjung Morawa. Bangunan sekolah ini masih berdiri dan sampai saat ini daerah ini disekitar sekolah ini sering kali disebut "SD Belanda" atau "Pondok Baskul" yang diambil dari nama sekolah aslinya (Ambasct School). Sekolah ini dikhususkan untuk anak-anak dari bangsawan dan pegawai yang bekerja 
di perkebunan ini. Guru yang diketahui pernah bekerja disekolah ini adalah Tan Malaka.

Kontribusi Senembah Maatchappij dalam perkembangan kualitas perkebunan di Sumatera Timur dibilang sangat besar, termasuk dalam bidang kualitas dan kesejahteraan buruhnya. Sarana yang diperuntukan untuk buruh dan pegawai diantaranya dibidang pendidikan, maskapai ini mendirikan sekolah yang diampu oleh Tan Malaka. Dibidang kesehatan, maskapai ini membangun Hopitaal Te Tandjong Morawa atau rumah sakit Tanjung Morawa yang sekarang dikenal dengan rumah sakit Dr. Gerhard Lumban Tobing (R.S. Dr. G.L. Tobing) yang masih berdiri. Berdasarkan paparan diatas, maka perlu usaha untuk menggali kembali sejarah tentang Senembah Maatschappij ini khususnya dalam hal buruh yang berperan didalamnya. mengingat tidak adanya yang meneliti secara spesifik keadaan buruh di Senembah Maatchappij sebagai salah satu kekayaan sejarah sosial di Sumatera Utara, khususnya di Kabupaten Deli Serdang maupun Kecamatan Tanjung Morawa. Oleh sebab itu, berdasarkan latar belakang diatas, peneliti akan melakukan penelitian berjudul "Buruh di Senembah Maatschappij 1889-1939" dalam suatu kajian sejarah.

Masalah-masalah yang dipecahkan dalam penelitian ini yaitu sejarah Berdirinya Senembah Maatchappij di Sumatera Timur; Bagaimana proses kedatangan buruh di Senembah Maatschaappij; keadaan buruh di Senembah Maatscappij dari mulai tahun 1889-1939.

Metode yang digunakan dalam penelitian ini adalah Metode sejarah serta Studi pustaka (Liblary Research). Metode sejarah adalah proses menguji dan menganalisis secara kritis rekaman dan peninggalan masa lampau (Gottschalk, 2008:39). Dalam hal ini peneliti akan melalui tahapan tahapan tertentu dalam meneliti sebagai mana tahapan-tahapan secara umum dikemukakan oleh Notosusanto (1971:17 dalam Sulasman, 2014:75), yaitu Heuristis, yaitu menghimpun jejak-jejak masa lalu; kritik Sumber (sejarah), yaitu menyelidiki apakah jejak itu sejati, baik isi maupun bentuknya; Interpretasi, yaitu menetapkan makna yang saling berhubungan dari fakta 
yang diperoleh dari sejarah itu. Penyajian, merupakan sintesis yang diperoleh dalam bentuk sebuah kisah.

\section{PEMBAHASAN}

\section{A. Latar Belakang Berdirinya Senembah Maatscappij.}

Dibukanya lahan perkebunan di wilayah Sumatera Timur, khususnya Kesultanan Serdang tidak terlepas dari akibat dari politik perluasan kekuasaan Belanda di Pulau Sumatera melalui Traktat London yang ditandatangani pada tanggal 17 Maret 1824 antara Inggris dan Belanda. Perjanjian ini adalah untuk mengakhiri persaingan antara Inggris-Belanda di Asia Tenggara (Pelzer, 1985:23) yang isinya Inggris menyerahkan Bengkulu sebagai gantinya Belanda menyerahkan Malaka, serta Belanda akan berhenti melakukan praktik monopoli perdagangan di Nusantara. Salah satu dampak dari perjanjian ini Belanda semakin leluasa berkuasa membuka membuka peluang bagi para pengusaha untuk membuka lahan perkebunan di Sumatera Timur.

Salah satu akibat dari takluknya seluruh kesultanan Melayu di Sumatera Timur, membuka jalan bagi para pengusaha-pengusaha untuk membuka lahan perkebunan di Sumatera Timur. Tidak dibenarkannya praktik monopoli yang dilakukan Belanda akibat Traktat London membuat para pengusaha non-Belanda mempunyai kesempatan yang sama dalam mengusahakan lahan perkebunan di Sumatera Timur. Lahirnya Traktat London tahun 1824 dan Traktat Siak tahun 1858 membuka jalan yang lebar bagi para pengusaha berkebangsaan Belanda maupun Non-Belanda untuk melakukan usahanya di sumatera. Senembah Maatschappij yang awal mulanya adalah sebuah firma yang didirikan oleh Naeher dan Grob tahun 1871 diberikan konsesi lahan oleh sultan Serdang yang notabene kekuasaanya sudah berada di tangan Belanda. Naeher dan Grob adalah pengusaha berkebangsaan Jerman dan Swiss, mendapatjan kesempatan yang sama dengan Nienhuys yang berkebangsaan Belanda dalam mengelola perkebunan tembakau di Sumatera timur. 


\section{B. Berdirinya Senembah Maatschappij.}

Pembukaan lahan perkebunan di Sumatera Timur oleh Deli Maatchappij pada tahun 1869 yang diperoleh melalui konsesi lahan dari Sultan Deli pada waktu itu menuai keberhasilan yang sangat memuaskan. Hasil komoditi tembakau berkualitas tinggi diekspor dan dipasarkan di luar negeri seperti di Bremen dan Rotterdam. Keberhasilan tersebut ternyata menarik pengusaha - pengusaha asing yang lain untuk membuka lahan perkebunan di kawasan ini. Deli Maatcshappij yang didirikan Oleh J. Nienhuys membuka lahan di daerah kekuasaan Kesultanan Deli atas jasa seorang Said Abdullah ibnu Bilsaqih yang menceritakan bahwa tembakau bermutu tinggi dapat ditanam di Medan dalam jumlah besar (Pelzer, 1985:51).

Salah satu pengusaha yang tertarik untuk membuka lahan perkebunan di Sumatera Timur adalah Carl Furchtegott Grob dan Hermann Naeher. Grob adalah seorang pengusaha berkebangsaan Jerman dan Naeher berkebangsaan Swiss. Grob sebelumya adalah seorang yang pernah bekerja pada sebuah Onderneming di Helvetia. Naeher adalah seorang pedagang di Sisilia yang datang ke Deli atas nasihat seorang relasi yang yang bermukim di Deli sebagai Tuan Kebun (Breman, 1997:76)

Awalnya mereka mendirikan sebuah firma yang kemudian mereka beri nama Firma Naeher \& Grob. Firma ini didirikan pada tahun 1871 dengan lahan yang didapat dari permohonan konsesi yang di wilayah kesultanan Serdang seluas 5300 hektar, yang pada awalnya mereka tanami dengan pala, kemudian tembakau (Breman, 1997:76). Pada Tahun 1889, lahan perkebunan firma ini telah membentang dikedua sisi lembah aliran Sungai Belumai mulai dari dekat pantai sampai ke pegunungan (Pelzer, 1985:60).

Di tahun-tahun pertama berdirinya firma Naeher \& Grob mengalami kemajuan yang pesat. Keahlian firma ini adalah memproduksi tembakau berdaun keras (Breman: 1997:76). Ciri-ciri daun tembakau yang diproduksi oleh firma ini yaitu tembakau dengan daun yang lebar, tebal dan berwarna hitam digunakan untuk industri cerutu yang dikenakan bea rendah. Selama kira-kira 20 tahun, onderneming-onderneming Naeher dan Grob mengirimkan produk mereka menggunakan sampan yang menghilir 
dan memperoleh persedian-persedian mereka melalui pelabuhan kecil di Rantau Panjang (Pelzer, 1985:60).

Perubahan selera jenis tembakau pada konsumen di Eropa menjadi memilih daun tembakau pembungkus yang bewarna muda ditambah penghapusan bea rendah bagi tembakau tebal yang menyebabkan kerugian dari firma ini. Masalah bertambah dengan memburuknya kesehatan Grob. Keadaan ini diperparah dengan penurunan harga tembakau pada tahun 1889, harga yang semula 1,46 gulden per pon turun menjadi 0,72 gulden per pon pada tahun 1890 (. Hal ini akibat terjadinya produksi yang berlebihan (overproduction) karena sangat cepatnya pertumbuhan areal perkebunan dan penanaman tembakau yang intensif maka pada tahun 1891 sebagian panen tembakau tidak terjual di pasar Amsterdam (Breman, 1997:69).

Keadaan diatas telah mendorong mereka untuk berniat menjual Firma ini. Atas saran dari direksi Deli Maatchappij yang sejak tahun 1875 membantu memasarkan hasil tembakau firma ini, Naeher dan Grob kemudian mereka kuasakan kekayaan (asset) mereka ke sebuah perseroan terbatas dan mereka menjual separuh sahamnya di bursa Amsterdam (Breman, 1997:76). firma Naeher dan Grob kemudian diubah bentuk badan usahanya menjadi Perseroan Terbatas dengan nama Naamlodze Venotchapp Senembah Maatschappij. Tanggal 30 September 1889, Anggaran Dasar maskapai ini disetujui oleh pemerintah kerajaan Belanda (Pelzer, 1985:61). Struktur pimpinan di Semembah Maatschappij antara lain C. W. Janssen sebagai direksi, sedangkan yang menjadi komisaris yaitu J. T. Cremer, H. Naeher, G. E. Haarsma, A. L. Wurfbain dan R. Von Seutter. (Janssen, 1939:5-7). Pada tahun 1914

Perubahan badan usaha membuahkan hasil yang nyata, perbaikan-perbaikan dilakuhan sehingga mendapatkan hasil yang baik. Walaupun kualitas tanah di Senembah Maatchappij kualitasnya tidak lebih unggul dari Deli Maatchappij, mutu tembakau di Senembah Maatchappij masih tergolong yang paling baik diantara perkebunan-perkebunan di Sumatera Timur. Penelitian menunjukkan tanah yang paling baik untuk penamaman tembakau adalah sepanjang batas sungai Wampu dengan Sungai Ular. Perluasan lahan dilakukan, Pada tahun 1889 konsesi tanah yang dimiliki 
seluas 31.563 bahu. Pada tahun 1897 bertambah menjadi 50.994 bahu, yaitu 40.340 terletak di wilayah Kesultanan Serdang dan 10.654 bahu berada di wilayah Kesultanan Deli (Janssen, 1939:11).

Perkebunan Senembah Maatschappij terletak di Pantai Timur Sumatera, memiliki 13 perkebunan di wilayah Kesultanan Serdang dan 1 perkebunan di masingmasing wilayah Kesultanan Deli dan Kesultanan Langkat. Pada tahun 1939, dari 15 perkebunan yang ada di Perkebunan Senembah Maatschappij, 11 merupakan perkebunan tembakau, yaitu Tanjung Morawa, Tanjung Morawa Kiri, Sei Bahasa, Batang Kuis, Petumbak, Gunung Rintih, Pagar Merbau, Two Rivers, Selayang, Kuala Namu dan Simpang Empat. Selain itu terdapat 3 perkebunan karet antara lain Tanjung Garboes, Melati dan Limau Mungkur dan 1 perkebunan kelapa yaitu Sei Tuan (Janssen, 1939:104).

Berdasarkan peta yang tertera dalam buku Janssen tahun 1939, Senembah Maatschaapij membawahi sebanyak 15 Onderneming di Sumatera Timur, Onderneming tersebut antara lain adalah Tandjong Morawa, Tandjong Morawa Kiri, Songei Bahasa, Batang Kwis, Patoembah, Goenoeng Rintih, Paggar Marbau, Two Rivers, Selajang, Kwala Namoe, Simpang Ampat, Tandjong Garboes, Melatti, Limau Mungkoer, Soengei Toean.

\section{Kedatangan Buruh (Kuli) di Senembah Maatschappij}

Pembukaan lahan perkebunan oleh perusahaan asing di Sumatera Timur mengakibatkan bertambahnya jumlah permintaan tenaga kerja untuk dipekerjakan sebagai buruh (kuli). Mereka itu nantinya dipekerjakan sebagai kuli penggarap tanah, menanam tembakau, mengolah daun-daun tembakau dan juga sebagai kuli angkut. Tembakau yang sudah dipanen diangkut ke bangsal-bangsal pengolahan dan sesudah selesai diolah, dikemas dan diangkut ke tempat-tempat pengiriman untuk diekspor ke pasaran dunia di Eropa.

Untuk mengatasi kekurangan tenaga kerja ini para pengusaha perkebuan harus mencari dan mendatangkan tenaga kerja dari luar Sumatera Timur. Mereka ada yang 
didatangkan dari Cina, India dan dari Jawa. Para tenaga kerja ini didatangkan dengan berbagai cara dan pengurusannya dilaksanakan oleh beberapa biro pencari tenaga kerja.

Adapun penempatan para buruh ke daerah yang spesifik di Sumatera Timur. Senembah Maatschappij yang berada di wilayah Serdang juga menjadi tujuan penempatan buruh dari Penang. Tahun 1888 sebanyak 352 kuli didatangkan ke Serdang, dan 442 kuli pada tahun 1889 (Azwar, 2004:71). Daerah penempatan yang lainnya tersebar di di Deli, Langkat, Asahan, Bedagei.

Pada mulanya kebutuhan tenaga kerja dipenuhi oleh agen pencari kuli yang ada di Penang dan Singapura, tetapi karena permintaan tenaga kerja yang semakin tinggi dari pihak perkebunan maka hal ini membuat para agen pencari kuli saling berlomba untuk memenuhi kebutuhan tersebut. Akibatnya, banyak calon kuli yang kurang sehat pun ikut dibawa ke Deli, dan ini sering dikeluhkan oleh pihak perkebunan. Untuk mengatasi masalah tersebut, maka untuk perkembangan selanjutnya proses pengerahan tenaga kerja dari Cina ini diurus oleh suatu Biro Imigrasi (Imigratie Bureau). Biro ini didirikan oleh para pengusaha yang tergabung dalam perhimpunan pengusahapengusaha perkebunan Deli (Deli Planters Vereniging atau DPV) termasuk didalamnya adalah perusahaan perkebunan Senembah Maatschappij. Melalui biro inilah para pengusaha itu menyelesaikan masalah-masalah yang dihadapi dalam mengelola perkebunan. Kuli-kuli yang didatangkan dari negeri Cina harus melalui Biro Imigrasi Protektorat Cina (Protector of Chinesse) di Singapura dan biro ini pula yang mengurus penampungan mereka sampai kuli-kuli itu dikirim ke perkebunanperkebunan tembakau di Deli.

Akan tetapi pada tahun 1899 selain Biro Imigrasi ada lagi suatu badan yang membantu mendatangkan kuli-kuli ke Sumatera Timur khususnya ke perusahaan Senembah Maatschappij yaitu Firma Bradley \& Co yang berkedudukan di Swataw (Cina bagian selatan). Firma Bradley \& Co mengirimkan kuli-kuli tersebut tidaklah secara langsung melainkan melalui Singapura terlebih dahulu, baru dikirimkan ke Deli, sedangkan Biro Imigrasi tidak melalui Singapura, tetapi dari Cina langsung ke Deli. 
Proses perekrutan tenaga kerja asal Jawa tidak jauh berbeda dengan kuli Cina. Caranya dengan menyebar agen atau yang biasa disebut werek ke desa-desa di Jawa. Pengiriman tenaga kerja dilakukan melalui agen yang berpusat di Semarang, Jawa Tengah dan dikirim ke Perkebunan Senembah Maatschappij melalui pelabuhan Belawan. Setelah proses pengiriman agen tenaga kerja ini biasanya menerima komisi dari perkebunan. Agar memperoleh komisi yang berlipat, tidak jarang agen tenaga kerja melakukan berbagai penipuan dan kecurangan. Mereka membujuk calon tenaga kerja dengan menyebut tanah Deli banyak emas dengan harga murah, banyak perempuan cantik, dan boleh berjudi. Setiap orang yang pergi ke tanah Deli, setelah beberapa tahun pulang kembali ke daerahnya sudah menjadi kaya.

Untuk meningkatkan pengerahan kuli Jawa, pada tahun 1911 didirikan biro tenaga kerja sendiri di Jawa dengan agen-agen di banyak tempat. Biro ini didirikan oleh Asosiasi Pengusaha Perkebunan atau Deli Planters Vereniging (D.P.V.). Pada tahun 1919 biro ini menjadi sebuah badan emigrasi khusus yang diberi nama Algemeen Delisch Emigratie Kantoor (A.D.E.K.) atau Kantor Emigrasi Umum Deli. Algemeen Delisch Emigratie Kantoor (A.D.E.K.) kemudian berubah nama menjadi Vrij Emigratie DPV en AVROS (V.E.D.A.), hal ini dikarenakan Perhimpunan Pengusaha Karet yang tergabung dalam Algemeene Vereniging Rubberplanters Oostkust van Sumatra (A.V.R.O.S.) bergabung dalam badan pengerahan kuli Jawa tersebut.

\section{Keadaan Ekonomi dan Sosial Buruh Senembah Maatschappij}

Dalam kesehariannnya para kuli yang bekerja di Senembah Maatchappij bekerja di perkebunan tembakau sesuai dengan aturan Koeli Ordonanntie yang berlaku. Jan Breman dalam bukunya Menjinakkan Sang Kuli, menyimpulkan pokokpokok dari Koeli Ordonnantie yang berlaku mulai dari tahun 1880, sebagai berikut :

- Bahwa tanpa ada kontrak tertulis tidak aka nada hubungan kerja.

- Kontrak itu harus didaftarkan kepada pemerintahan setempat segera sesudah datangnya kuli. Kontrak dibuat dengan menyebutkan nama, jenis pekerjaan, dan cara pembayaran upah berpegang pada hari kerja sepuluh 
jam dan dan masa kontrak selama-lamanya tiga tahun. Pejabat itu memastikan apakah kontrak dilakukan dengan sukarela.

- Bahwa buruh dengan setia harus melaksanakan apa yang dibebankan kepadanya dan tanpa izin tertulis tidak boleh meninggalkan perkebunan. Sebaliknya majikan wajib mengeluarkan izin apabila jika seorang kuli ingin mengadu pada pemerintah setempat karena mendapat perlakuan buruk, sebagai perorangan.

- Bahwa buruh berhak mendapatkan perlakuan baik (upah tetap, perumahan, air untuk mandi dan minum dan perawatan kesehatan).

- Bahwa setelah menyelesaikan kontrak, buruh kalau memang menghendaki harus dikembalikan ke tempat ia semula menjadi buruh. (Breman, 1997:42)

Demikian pokok pokok dari ordonansi kuli yang berlaku di Sumatera Timur. Kebijakan tersebut mengena pada buruh yang bekerja di seluruh perkebunan di Sumatera Timur termasuk Senembah Maatschappij. Selain kewajiban yang dibebankan oleh para buruh, terdapat hukuman bagi para buruh yang melarikan diri atau tidak mau bekerja. Juga dapat dihukum jika memberontak, menghina atau mengancam majikan atau pengawas, mengganggu keamanan, mengasut orang lain untuk lari atau membangkan, berkelahi, mabuk mabukan, bahkan melakukan semacam perbuatan yang dianggap melanggar, sekalipun tidak melanggar perjanjian itu sendiri (Breman, 1997:43).

Setiap pelanggaran ordonansi kuli yang dilakukan oleh buruh akan dijatuhkan sanksi (Poenale Sanctie). Hukuman dijatuhkan setelah dilakukan penyelidikan atas pengaduan yang ada oleh pengadilan. Penjatuhan hukuman semula dipercayakan dilakukan oleh residen, kemudian kepada kontrolir di ibukota daerah terdekat tempat perkebunan berada.

Sesuai dengan Ordonansi kuli yang tertera diatas, maka kuli memiliki jam kerja selama 10 jam dalam sehari. Namun dalam prakteknya para buruh bisa bekerja lebih lama dari jam kerja yang sudah ditentukan. Mereka harus berusaha tiba di ladang kerja lebih awal dikarenakan jauhnya lokasi ladang dengan permukiman dan baru boleh kembali jika kerja borongan yang telah ditetapkan sebelumnya telah selesai. Akibatnya 
tidak jarang para kuli bekerja jauh lebih lama dari dari waktu yang ditentukan hingga mencapai satu hingga dua jam lebih lama (Breman (1997:103).

Satu tahun penenaman tembakau dibagi menjadi dua dua musim, yaitu masa ladang dan masa lumbung. Pekerjaan menyiapkan landang terutama dilakukan oleh kuli Jawa Kuli Keling, dan pekerja yang dikerahkan dari sekitar perkebunan. Mereka menyiapkan lahan untuk penanaman baru, membabat hutan, mencangkul dan meratakan tanah, membuat guludan tanaman dan menggali parit pembuangan air, membangun lumbung untuk mengeringkan tembakau dan barak untuk kul, diantara satu dan lain ladang dibuat perbatasan. Kegiatan ini berlangsung dari bulan Agustus dan berlangsung terus hingga bulan Januari.

Pada awal tahun yang baru, tugas berganti dengan kuli Cina yang lebih berpengalaman. Mereka membakar ladang masing-masing dan membersihkannya. Mereka merawat petak-petak persemaian yang mereka buat saat itu juga. Setelah enam minggu (Maret-April) mulailah mereka memindahkan tanaman muda, per ladang sekitar 16.000 batang. Pada akhir daur kerja, perkebunan membayar para penanam sesuai dengan jumlah tanaman yang dihasilkan.

Lain halnya dengan keseharian para kuli di perkebunan karet. Kuli-kuli Jawa di perkebunan karet harus melakukan 3 pekerjaan. Pertama, pekerjaan penanaman pohonpohon karet, Kedua, harus menyadap karet, Ketiga, harus bekerja di emplassemen yaitu tempat memproses getah karet menjadi karet mentah. Para kuli harus bangun pukul 5 pagi untuk menanam pohon karet. Dalam penanaman karet, barisan pohon harus peratur dan ditanam dengan cermat. Di samping tiap-tiap pohon karet diberi tongkat dan nomor. Selanjutnya bekerja di emplassemen untuk memproses getah karet yang telah disadap dan diletakkan pada penampungan. Akhirnya kuli-kuli baru bisa kembali pulang ke rumah pondoknya pada pukul 6 sore. (Suprayitno, 2004:9)

Keseharian para buruh yang digambarkan oleh Tan Malaka ketika bertugas di Senembah Maatschappij bulan Desember tahun 1919 sampai Juni tahun 1921 hihup serba kekurangan. Dalam tulisannya : 
Kuli kebun, laki-laki atau perempuan biasanya mesti bangun pukul 4 pagi, karena kebun tempat mereka bekerja jauh letaknya. Pukul 7 atau 8 malam barulah mereka tiba dirumah. Gaji menurut kontrak $f$ 0,40 sehari. Makanan biasanya tidak cukup untuk kerja keras mencangkul ditempat panas 8 sampai 12 jam sehari. Pakaianpun lekas rombeng-rombeng lantaran sering kerja di hutan. (Malaka, 2000:74)

Keadaan yang serba kekurangan mendorong para kuli untuk melakukan hal yang diluar dugaan. Seperti kuli perempuan yang rela melacur demi memenuhi kebutuhannya sehari hari. Sedangkan yang kuli lain mengadu nasib dengan berjudi di setiap hari gajian, belum lagi potongan-potongan yang mereka dapatkan. Menariknya kedaan yang demikian memang dibiarkan tercipta, guna menciptakan ikatan kerja antara maskapai dengan buruh melalui hutang yang diberikan maskapai kepada buruh.

Kekurangan dalam segala-gala itu menimbulkan nafsu yang tak tertahan buat menguji nasib dengan jalan main judi, nafsu yang sengaja dibangunkan oleh maskapai sesudah hari gajian. Yang kalah berjudi - dan biasanya lebih banyak yang kalah dari pada yang menang - diijinkan berhutang. Karena terikat hutang, 90 dari 100 kuli yang sudah lepas kontraknya terpaksa menekan kontrak lagi. Hutang menimbulkan keinginan berjudi, dan perjudian menambah hutang terus menerus. (Malaka, 2000:74)

Bagi pekerja wanita yang tak bersuami dikenakan potongan yang panjarnya 3 dollar, sebanyak setengah dollar, dipotong pula sebanyak sepertiga dollar untuk harga cangkol, hingga dengan demikian ia hanya akan menerima tidak lebih dari 2.20 dollar untuk keperluan hidupnya. Maka tidak heran bahwa mereka umumnya menjadi pelacur! (Said, 1977:79)

Dalam tulisan Tan Malaka, kuli di Senembah Maatschappij mendapat gaji $f$ 0.40 perhari dengan jam kerja 8 hingga 12 jam. Lebih lanjut dikemukakannya, hanya satu atau dua diantara 1000 orang yang mempunyai sedikit harapan untuk naik pangkat, ada yang yang dijadikan mandor ataupun hopmandor, ada yang diterima menjadi pengawal bengkel mobil, mesin listrik ataupun rumah sakit. Tetapi tetap terlampau 
rendah $f 20-f 30$ sebulan untuk mandor dan $f 60$ untuk hopmandor, dengan 15-20 tahun bekerja (Malaka, 2000:75).

Terjadi kesenjangan yang sangat lebar antara kuli dan orang Eropa di Senembah Maatschappij. Perbedaan gaji yang cukup mencolok antara kedua golongan ini. Lebih lanjut diungkap oleh Tan Malaka :

“.. Kalau saya tidak salah, diluar gaji puluhan ribu setahun itu, tuan kebun mendapatkan bahagian untuk $f$ 200.000. tuan maskapai lebih lebih lagi. Tidak saja mendapat gaji tetap sebagai direktur dan adviseur dari beberapa maskapai, mendapat untung dari bunga modal yang ditanamnya, tetapi juga menerima bagian yang lebih besar dari untung kebun.' (Malaka, 2000:73)

Di lingkungan kuli-kuli Cina terdapat orang-orang yang berfungsi sebagai koordinator pekerja yang mengurus kebutuhan pekerja sehari-hari. Seorang Tandil Cina mendapat upah 319 dolar setahun sedangkan seorang kuli dilapangan hanya 135 dolar dan seorang kuli di kongsi mendapat upah hanya 72 dolar, Kuli India (Keling) 72 dolar. Setiap tenaga kerja tidak sama upahnya baik upah kuli maupun upah mandor. Mandor besar orang Jawa mendapat 258 dolar setahun, mandor biasa 135 dolar dan kuli biasa 80 dolar (Said, 1977:80).

Selama penelitian, peneliti tidak menemukan bukti yang mengarah langsung penggunaan uang kebun (token) di lingkungan onderneming - onderneming Senembah Maatschappij. Tetapi disekitar wilayah dari Senembah Maatschappij menggunakan uang kebun sebagai mata uang yang berlaku. Onderneming sekitar Senembah Maatschappij yang menggunakannya antara lain, Onderneming Wampu dan kuala begumit (disekitar Onderneming Selajang), Onderneming Galia (di sebelah timur onderneming Gunung Rintih), dan Onderneming Tanah Raja (sebelah timur onderneming Simpang Ampat)

Dibidang kesehatan yang dilakukan oleh Senembah Maatschappij adalah melanjutkan pengoperasian rumah sakit yang dikenal sebagai Centraal Hospitaal Te Tandjong Morawa (Janssen, 1939:30) yang sudah berdiri sejak masa Firma Naeher \& Grob. Rumah Sakit Pusat Tanjung Morawa berfungsi sebagai pusat pelayanan 
kesehatan di Perkebunan Senembah Maatschappij. Kuli yang menderita suatu penyakit akan dibawa ke poliklinik yang ada di setiap perkebunan. Beberpa poliklinik antara lain terdapat di perkebunan Gunung Rintih, Petumbak dan Sei Bahasa (Janssen, 1939:30). Untuk penyakit yang ringan dan tidak terlalu membahayakan diobati di poliklinik tersebut. Kuli yang menderita penyakit yang parah dan berbahaya akan dibawa ke rumah sakit pusat. Kuli dibawa dengan menggunakan transportasi bendi atau alat transportasi lain.

Dalam hal pendidikan, Senembah Maatschappij menaruh perhatian khusus atas pendidikan anak-anak kuli yang bekerja di perkebunannya. Dr. C.W. Jannsen (direktur Senembah Maatchappij) mengupayakan agar anak-anak dan remaja mendapatkan pendidikan, bukan hanya membaca, menulis, dan berhitung melainkan juga pendidikan praktek. Maka dari itu ia menggagas dibagun sekolah yang diperuntukan untuk anakanak kuli di Senembah Maatschappij. Tujuannya, agar dikemudian hari dapat dipekerjakan di perkebunan dan menghindari Poenale Sanctie karena sudah biasa bekerja (Janssen, 1939:70).

Sistem Pendidikan di Senembah Maatchappij tidak menggunakan bahasa Melayu sebagai bahasa pengantar akan tetapi menggunakan bahasa Jawa. Dr. C.W. Janssen menolak menggunakan bahasa Melayu sebagai bahasa pengantar sesuai dengan program Pendidikan dasar pemerintah (Pelzer, 1985:61). Dr. C.W. Janssen menugaskan seorang bernama de Way untuk mencari guru di Jawa pada akhir tahun 1919. Pada tahun 1920, de Way datang dengan membawa guru Jawa, yang akan mendidik anak-anak dalam bahasa Jawa dan juga Adat Jawa (Janssen, 1939:70).

Salah seorang guru yang pernah mengajar di sekolah yang dibagun di Senembah Maatchappij adalah Tan Malaka. Dr. C.W. Janssen menawarkan kepada Tan Malaka untuk bekerja di Senembah Maatschappij pada saat keduanya masih di Amsterdam. Tan Malaka ditugaskan bekerjasama dengan de Way untuk menemukan sistem pendidikan yang cocok dengan keadaan di Senembah Maatscappij (Malaka, 2000:100). Tan malaka ditugaskan di Kantor Pusat Senembah Maatchappij di Tanjung Morawa . 
Selain kursus, membaca, menulis dan berkebun Senembah Maatschappij Ambachtsschool, yaitu sekolah teknik yang mempelajari tentang tentang pertukangan. Di sekolah ini siswa diajari tentang ilmu pertukangan dan perbengkelan. Nantinya siswa-siswa ini akan dipekerjakan di pabrik-pabrik di senembah maatscappij.

\section{PENUTUP}

Dari hasil penelitian yang diperoleh dari berbagai sumber yang telah dituangkan dalam pembahasan, Maka dapat ditarik kesimpulan sebagai berikut Dibukanya lahan perkebunan di wilayah Sumatera Timur, khususnya Kesultanan Serdang tidak terlepas dari akibat dari politik perluasan kekuasaan Belanda di Pulau melalui Traktat London yang ditandatangani pada tanggal 17 Maret 1824 antara Inggris dan Belanda.

Salah satu dampak dari perjanjian ini Belanda semakin leluasa berkuasa membuka membuka peluang bagi para pengusaha untuk membuka lahan perkebunan di Sumatera Timur. Jacobus Nienhuys kemudian datang dan mendirikannya Deli Maatchappij olehnya tahun 1869, disusul kemudian oleh Carl Furchtegott Grob dan Hermann Naeher. Grob merupakan seorang pengusaha dari Sisilia berkebangsaan Jerman yang pernah bekerja di Onderneming Helvetia dan Naeher seorang berkebangsaan Swiss. Mereka membentuk sebuah Firma perkebunan yang diberi nama Firma Naeher \& Grob pada tahun 1871 dengan lahan yang berasal dari konsesi lahan di sepanjang Sungai Belumai yang diberikan oleh Sultan Serdang. Firma inilah yang kemudian menjadi cikal bakal berdirinya Senembah Maatchappij.

Buruh menjadi tenaga kerja di Senembah Maatschappij yang sering disebut dengan istilah Kuli didatangkan kebanyakan dari China dan Jawa. Buruh china didatangkan melalui agen-agen di Strait Settlement dan juga langsung dari China daratan. Buruh Jawa didatangkan dari Pulau Jawa. Kedatangan buruh tidak lepas dari peran perusahaan penyalur tenaga kerja seperti ESAS, DPV dan VEDA.

Kehidupan kuli di Senembah Maatscappij tidak layak, terbitnya Koeli Ordonnantie dan berlakunya Poenale Sanctie terhadap kuli berimbas pada tingkat 
kesejahteraan yang sangat rendah. Namun tahun-tahun berikutnya terjadi peningkatan kesejahteraan kuli karena mulai diperhatikannya nasib para buruh oleh direktur Senembah Maatschappij Dr. C.W. Janssen. Perbaikan-perbaikan itu meliputi upah, permukiman, kesehatan dan pendidikan.

Permukiman buruh didominasi rumah- rumah barak itu berdinding bambu dan atapnya terbuat dari ilalang atau ada juga dari daun rumbia. Barak-barak seperti itulah yang kemudian digunakan bagi kuli sebagai tempat tinggal. Satu barak dapat dihuni oleh ratusan kuli. tempat tinggal kuli-kuli Jawa yang ditempatkan dalam barak-barak yang terpisah dari kuli-kuli Cina. Antara barak yang satu dengan barak yang lainnya saling berjauhan walaupun tetap berada di sekitar perkebunan, hal ini sengaja dibangun agar kuli-kuli itu tidak terlalu lama menuju ketempat kerja.

Untuk urusan kesehatan Senembah Maatschappij melanjutkan pengoperasian rumah sakit yang dikenal sebagai Centraal Hospitaal Te Tandjong Morawa yang sudah berdiri sejak masa Firma Naeher \& Grob. Rumah Sakit Pusat Tanjung Morawa berfungsi sebagai pusat pelayanan kesehatan di Perkebunan Senembah Maatschappij.

Dalam hal pendidikan, Senembah Maatschappij menaruh perhatian khusus atas pendidikan anak-anak kuli yang bekerja di perkebunannya. Dr. C.W. Jannsen (direktur Senembah Maatchappij) mengupayakan agar anak-anak dan remaja mendapatkan pendidikan, bukan hanya membaca, menulis, dan berhitung melainkan juga pendidikan praktek. Maka dari itu ia menggagas dibagun sekolah yang diperuntukan untuk anakanak kuli di Senembah Maatschappij. Sistem Pendidikan di Senembah Maatchappij tidak menggunakan bahasa Melayu sebagai bahasa pengantar akan tetapi menggunakan bahasa Jawa

Tan malaka Mengungkap adanya desa Potemkin di Senembah Maatschappij. Yaitu yaitu kampung yang sengaja dibuatkan untuk pencitraan bahwa kuli di Senembah Maatcshappij memiliki taraf kesejahteraan yang layak. Adanya desa dan sekolah "Potemkin" merupakan suatu gagasan yang baru didalam lingkungan perkebunan di Sumatera Timur. 


\section{Daftar Pustaka}

Azwar, T. Keizerina Devi (2004). Poenale Sanctie: Studi Tentang Globalisasi Ekonomi dan Perubahan Hukum di Sumatera Timur (1870-1950). Medan: Program Pasca Sarjana USU

Bremen, Jan (1997). Menjinakkan Sang Kuli : Politik Kolonial, Tuan Kebun, dan Kuli di Sumatera Timur pada Awak Abad-20. Jakarta : Pustaka Utama

Gilissen, Theodore (1927). Sumatra Tobacco Companies. Amsterdam. Tanpa Penerbit.

Gottsschalk, Louis (2008). Mengerti Sejarah, Terjemahan Nugroho Notosusanto. Jakarta : UI-Press

Janssen, C.W \& H.J Bool (1939). Senembah Maatchappij 1889-1939. Amsterdam: Boek- en kunstdrukkerij v/h Roeloffzen-Hübner en Van Santen.

Kanumoyoso, Bondan (2001). Nasionalisasi Perusahaan di Indonesia. Jakarta : Sinar Harapan.

Kartodirdjo, Sartono \& Djoko Suryo (1991). Sejarah Perkebunan Indonesia, Kajian Sosial - Ekonomi.Yogyakarta : Aditya media

Malaka, Tan (2000). Dari Penjara ke Penjara : Bagian I. Jakarta : Teplok Press

Said, M (1977). Koeli Kontrak Tenpoe Doeloe dengan Derita dan Kemarahannya. Medan : Waspada

Sjamsuddin, Helius (2012). Metodologi Sejarah. Yogyakarta : Ombak

Sinar, Lukman (1971). Sari Sedjarah Serdang : Jilid I. Medan

Sulasman (2014). Metodologi Penelitian Sejarah. Bandung : Pustaka Setia

Suprayitno, Indera (2004). Pengaruh Pertumbuhan Industri Karet Terhadap Kuli Kontrak Di Sumatera Timur 1904-1920. Medan : e-USU Repository Universitas Sumatera Utara.

Pelly, Usman Dkk (1986). Sejarah Pertumbuhan Pemerintahan Kesultanan Langkat, Deli dan Serdang. Proyek Inventasisasi dan Dokumentasi Sejarah Nasional (IDSN) Departemen Pendidikan dan Kebudayaan RI 1985-1986.

Pelzer, Karl (1985). Toean Keboen dan Petani : Politik Kolonial dan Perjuangan Agraria di Sumatera Timur 1863-1947. Jakarta : Sinar Harapan. 